University of Massachusetts Amherst

ScholarWorks@UMass Amherst

UMass Institute for Global Health Faculty

Publications

UMass Institute for Global Health

2008

\title{
Assuring Adequate Protections in International Health Research: A Principled Justification and Practical Recommendations for the Role of Community Oversight
}

David Buchanan

University of Massachusetts - Amherst, buchanan@schoolph.umass.edu

Follow this and additional works at: https://scholarworks.umass.edu/umigh_faculty_pubs

Part of the Public Health Commons

\section{Recommended Citation}

Buchanan, David, "Assuring Adequate Protections in International Health Research: A Principled Justification and Practical Recommendations for the Role of Community Oversight" (2008). Public Health Ethics. 2.

Retrieved from https://scholarworks.umass.edu/umigh_faculty_pubs/2 
Journal: $\quad$ PUBLIC HEALTH ETHICS

Article doi: $\quad$ phn027

Article title: Assuring Adequate Protections in International Health Research: A Principled Justification and Practical Recommendations for the Role of Community Oversight

First Author: David Buchanan

Corr. Author: David Buchanan

\section{AUTHOR QUERIES - TO BE ANSWERED BY THE CORRESPONDING AUTHOR}

The following queries have arisen during the typesetting of your manuscript. Please answer these queries by marking the required corrections at the appropriate point in the text.

\begin{tabular}{|c|c|}
\hline A1 & $\begin{array}{l}\text { Author: Please see the sentence 'In that research, pregnant women in low-income...' } \\
\text { on page } 1 \text {, line } 47 \text { Please check if the alterations are correct. }\end{array}$ \\
\hline A2 & Author: Please check the suggested running head. \\
\hline A3 & $\begin{array}{l}\text { Author: Please check if the alteration in the sentence "As described below, when novel } \\
\text { interventions hold..." on page } 4 \text {, line } 335 \text { is correct. }\end{array}$ \\
\hline A4 & $\begin{array}{l}\text { Author: The sentence 'For our purposes here, it is worth recalling that...' on page } 6 \text {, } \\
\text { line } 586 \text { is not clear because of the term' city-states'. Does it mean relationship between } \\
\text { cities and states or relationship between states that are cities? }\end{array}$ \\
\hline A5 & $\begin{array}{l}\text { Author: Please see the sentence 'There, we recommend that CAB members should...' } \\
\text { on page } 8 \text {, line } 778 \text {. Please replace, if possible, the part' see below' with some other } \\
\text { phrase, such as one that directs to a section etc. }\end{array}$ \\
\hline A6 & $\begin{array}{l}\text { Author: Please see the sentence 'Third, we recommend that one of the two...' on page } \\
778 \text {, line } 793 \text {. Since the sentence is about the Community Advisory Board, is the part' } \\
\text { at the local level' necessary? }\end{array}$ \\
\hline A7 & $\begin{array}{l}\text { Author: Please check the alterations made in the sentence 'But over time, we envision } \\
\text { that CABs...' on page } 9 \text {, line } 863 \text {. }\end{array}$ \\
\hline A8 & $\begin{array}{l}\text { Author: Please see the references Sandel, } 1982 \text { and Taylor, 1985. Please confirm which } \\
\text { Cambridge they are-UK or MA. }\end{array}$ \\
\hline
\end{tabular}




\title{
Assuring Adequate Protections in
} Justification and Practical Recommendations for the Role of Community Oversight

\author{
David Buchanan*, University of Massachusetts, Amherst \\ Sibusiso Sifunda, Medical Research Council, Capetown, South Africa \\ Nasheen Naidoo, Medical Research Council, Capetown, South Africa \\ Shamagonam James, Medical Research Council, Durban, South Africa \\ Priscilla Reddy, Medical Research Council, Capetown, South Africa
}

*Corresponding author: 306 Arnold House, School of Public Health \& Health Sciences, University of Massachusetts, Amherst, MA 01003, USA. Tel.: (413) 545 1005; Email: Buchanan@schoolph.umass.edu.

The analysis presented here lays out the ethical warrants for requiring community oversight of health research conducted in international settings. It reviews the inadequacies with the current standards of individual informed consent and research ethics committee review, and then, shows how a broader population-based public health perspective raises new demands on justice involving due consideration of the rights, harms and benefits to the community as a whole. As developed here, an ethical standard that requires community oversight of health research is justified on three principled grounds: respect for community autonomy and their right to selfdetermination; due consideration of the consequences of the research for the community as a whole; and, a more complete understanding of human autonomy. The paper concludes with practical recommendations regarding the composition of Community Advisory Boards to ensure that they have legitimate decision-making authority in diverse socio-cultural contexts.

\section{Introduction}

Since the conduct of the controversial HIV-perinatal

transmission trials in the early 1990s, debates have raged about the ethics of international health studies. In that research, pregnant women in low-income countries were given low doses of AZT to determine whether a less expensive alternative could be developed to prevent mother-to-infant transmission of HIV (Angell, 1997, 2000; Lurie and Wolfe, 1997). The research raised serious questions about the potential for exploitation and the adequacy of present protections for participants in international health research.

In response to these controversies, a number of bioethicists have recently issued calls to mandate com- munity involvement in decision-making about the conduct of health research (Weijer and Emanuel, 2000; Emanuel et al., 2004; Brody et al., 2005). One major concern raised by these analyses is whether Research Ethics Committee (REC) reviews and individual informed consent provide sufficient ethical safeguards in all contexts (Macklin, 2004).

Key issues left unresolved by these calls are both the theoretical foundation that could provide the ethical justification for community monitoring and practical strategies for instituting an oversight process with legitimized authority. To advance the development of sound context-appropriate ethical standards, this paper presents a principled justification for the ethical assessment of international health research protocols by community representatives. In addition, recommendations 
regarding a feasible process for achieving community oversight are provided.

From the outset, it is important to address potential concerns that requiring an additional layer of review might impede the timely conduct of research (Berkley, 2003; Dawson and Kass, 2005). A vastly disproportionate share of the world's research resources is now allocated to studies on diseases that affect only a minority of the global population (Global Forum, 2004). Additional review requirements on international health research would be unjust if the net result served only to decrease access to the benefits of research further for the majority of the world's population.

Our view is that, requiring another level of review is necessary, not only to ensure ethically appropriate oversight, but also to facilitate the conduct of research by building trust in its safety and importance. In Western industrialized nations, there has been a 'paradigm shift' in public attitudes toward research participation, where the weight of concerns has shifted from apprehension about the risks of research participation to an appreciation of the potential benefits (Kahn et al., 1998; McCarthy, 1998; Powers, 1998; Buchanan and Miller, 2006a). With the onset of the AIDS epidemic, the urgent need for effective treatments led many people to view research participation not as a pernicious threat, but as an opportunity to obtain the most scientifically advanced therapies possible. Since community monitoring should reduce the threat of exploitation and thereby increase trust in its potential benefits, specifying clear policies with respect to the purpose and parameters of community review should bolster confidence among potential research volunteers, and thus facilitate the conduct of research in these settings.

The paper starts with a synopsis of concerns that have been raised about the processes of individual informed consent and REC review. We then examine recent issues that have emerged from the field of public health ethics regarding the adequacy of currently accepted ethical review procedures, which were designed primarily to monitor clinical treatment trials, and growing recognition of the need to take into account population protections. Building on that framework, we present the ethical rationale for community involvement in assessing the ethical conduct of health research. Community oversight refers to a process of engaging community members equitably in monitoring health intervention research to of community members protected. The paper concludes of community members protected. The paper concludes with practical recommendations regarding issues of representation to ensure fair community participation in monitoring health research.

Problems with Individual Informed Consent

A number of concerns have been raised about the adequacy and appropriateness of the individual informed consent standard in the context of international health research. These concerns include: the definition of 'informed' and criteria for assessing its attainment; the cultural appropriateness of individualistic decision-making processes; concerns about the priority of individual autonomy over other moral considerations; questions about the utility of individual informed consent per se; and, finally, reconsiderations of the overarching purpose of informed consent requirements.

Faden and Beauchamp (1986) make a distinction between 'philosophical' and 'policy-oriented' definitions of informed consent. A philosophical definition refers to a substantial understanding of the overall research process and its implications for human interests. A policyoriented definition refers to the legal requirements enumerated in state law, such as the US Code of Federal Regulations (45 CFR 46.116(c) and 45 CFR 46.116(d)), which denotes eight elements (see box) that must be presented in written informed consent documents.

\section{Eight Elements of Informed Consent}

The eight required elements of informed consent that have been defined by US federal regulations [ 45 CFR 46.116(c) and 45 CFR 46.116(d)] are

1. a statement that the study involves research, an explanation of the purposes of the research and the expected duration of the subject's participation, a description of the procedures to be followed, and identification of any procedures which are experimental

2. a description of any reasonably foreseeable risks or discomforts to the subjects

3. a description of any benefits to the subjects or to others which may reasonably be expected from the research

4. a disclosure of appropriate alternative procedures or courses of treatment, if any, that might be advantageous to the subjects

5. a statement describing the extent, if any, to which confidentiality of records identify the subjects will be maintained

6. for research involving more than minimal risk, an explanation as to whether any compensation and an explanation as to whether any medical treatments are available if injury occurs and, if 
so, what they consist of, and where further information may be obtained

7. an explanation of whom to contact for answers to pertinent questions about the research and research subjects' rights, and whom to contact in the event of a research-related injury to the subjects

8. a statement that participation is voluntary, refusal to participate will involve no penalty or loss of benefits to which the subjects is otherwise entitled, and the subjects may discontinue participation at any time without penalty or loss of benefits to which the subjects is otherwise entitled.

While some legal provisions are designed to foster the conditions in which the substantive philosophical ideal can be attained, there are currently no established standards or criteria for determining the degree to which individuals truly understand what their participation entails. Critically, there is a much greater distance between the philosophical ideal and the reality of individual comprehension in contexts where participants may lack formal education, be illiterate, live in poverty, be malnourished or face other stressful life conditions. Furthermore, researchers and others have noted that many languages do not have words or equivalent concepts for basic terminology such as 'research' or 'hypothesis', let alone more technical scientific language such as 'placebo', 'false positives', and 'randomization' (Ekunwe and Kessel, 1984; Bayer, 1998; Moodley, 2002; MacQueen et al., 2004; Molyneux et al., 2004; Dawson and Kass, 2005). More broadly, many socio-cultural conceptual frameworks regarding the etiology of disease are incongruent with Western scientific explanations. In such contexts, while the eight elements of informed consent can perhaps be satisfactorily explained to potential participants (thus fulfilling the policy-oriented definition of informed consent), it is difficult to maintain that they have a proficient understanding of the nature, goals and risks of the research, which is fundamental to providing one's permission for researchers to proceed with the experiment. The common requirement that informed consent documents be written in plain language fails to address this important ethical problem.

Issues have also been raised about the imposition of Western norms of individual decision-making in contexts where such practices are foreign (Moodley, 2002; Dawson and Kass, 2005; Woodsong and Karim, 2005). The (Western) concern that others may exert undue influence may be based on the questionable assumption that the interests of the individual and the community are inherently in conflict. In different cultural contexts, however, social relationships may be understood to be (at least partially) constitutive of one's identity; for example, the traditional African concept of 'ubuntu' has been defined as 'umuntu ngumuntu ngabantu' - 'you are who you are because of other people' (Biko, 1978). In the West, Sandel (1982) has described this broader self-understanding as a shift from thinking in terms of 'I' to 'we', where one's sense of identity is bound up with the realization of a common way of life, the reproduction of valued social practices, and the sense of community in which one takes pride. In such contexts, not only are the interests of the individual and the community commonly perceived to be synonymous, but the notion that persons should make decisions independently, divorced from their social relationships, is a patent violation of accepted social norms. The current push for requiring individual informed consent in all contexts appears to be based on the tacit assumption that low-income countries are traditional societies that have not yet attained a modern, enlightened mindset, in the sense of the emancipation of the individual and valorization of individual rights (Mamdani, 1996). This trajectory is apparently presumed to be unilinear, universal and normal, rather than historically contingent or problematic, where the possibility of developing ethical norms along divergent lines might remain open. In light of these opposing considerations, the proposed standards presented here seek to achieve an appropriate balance between concerns about the potential for individual exploitation and the need for respecting beneficent cultural practices.

Critics have also questioned the near-absolute priority placed on the principle of respect for individual autonomy (from which the mandate for individual informed consent derives) over other moral considerations in the brief history of bioethics, as it developed in the US (Weijer, 1999; Rhodes, 2005). As Levine (1986) notes, the work of the 1978 US National Commission must be seen in context of its time and thus can be faulted now for its overemphasis on individual rights, to the neglect of obligations to the larger community. More strongly, Taylor (1985) has assailed the central tenet of liberalism, which he calls the 'primacy of rights', referring to the moral view that individual rights have priority over all other moral considerations, such as obligations to contribute to the collective good. However, as the well-known 1905 US Supreme Court ruling in Jacobsen v. Massachusetts made clear, the principle of individual freedom cannot take absolute precedence over other moral principles. On the contrary, since the potential benefits to society and future generations are significant, other ethicists have taken the position that citizens should be morally obligated to 
participate in research, in order to advance the common good, distribute risk equitably, and mitigate the free-rider problem (Caplan, 1984; Harris, 2005; Orentlicher, 2005; Rhodes, 2005).

Moreover, Truog and his colleagues (Truog, Robinson, and Randolph, 1999) have questioned the 'blind insistence' on obtaining individual informed consent. As they state, 'There is little evidence to support the claim that informed consent, as currently practiced, provides protection against the exploitation of patients in research. Studies have shown that patients rarely have an adequate understanding of consent forms and often do not understand the meaning or implications of randomization.' In its stead, they propose the use of a 'reasonable person standard', which could be achieved by 'the involvement of the community through the representation of people without medical backgrounds' on ethical review boards.

Finally, while great emphasis has been placed on the need for demonstrating respect for individual autonomy, another key purpose of informed consent has centered on reducing inequalities of power and knowledge (President's Commission, 1982). As described below, when novel interventions hold the potential for affecting the community as a whole, there is a critical need for putting processes in place that reduce inequalities of power between research institutions and communities targeted as potential pools for participant recruitment and eventual dissemination. Current interest in USA in CommunityBased Participatory Research (CBPR) appears to be directly related to reducing power differentials and mitigating these ethical concerns (Wallerstein et al., 2005; Buchanan et al., 2007). In many types of research, it is the community as a whole that both bears the risks and stands to gain the potential benefits of newly developed interventions. New policies are thus imperative for redressing power imbalances and giving due consideration to the community's right to self-determination.

\section{Problems with Research Ethics Committee Review}

A number of concerns have also been raised about the adequacy of the research ethics review process, including the composition, training, scope of authority, accountability and allegiance of review boards (Emanuel et al., 2004). The following analysis focuses primarily on the US system of Institutional Review Boards (IRBs), and thus similar systems of research ethics review.

In a policy formulation that has since been called into question, the US Congress passed regulations that cre-

ated a decentralized system of ethical review boards and that enumerated only minimal requirements regarding the composition of local IRBs. According to these regulations, IRBs must have at least five members 'with varying backgrounds to promote... sensitivity to such issues as community attitudes', 'at least one member whose primary concerns are in non-scientific areas', and 'at least one member who is not otherwise affiliated with the institution' (US 45 CFR 46.116). In practice, this has generally meant that institutions appoint one outside community member to sit on a board with 10-12 other members recruited from the ranks of experienced researchers employed by the university or research organization. As a result, Marshall (2007, p. 17) notes that 'most are dominated by scientists who are responsible for reviewing the research protocols of colleagues and friends.' US regulations do not provide any further guidance with respect to how members should be selected.

Until quite recently, there were no requirements in the US regarding the training or qualifications of IRB members. In the wake of widespread public outcry over the deaths of two research participants several years ago, however, the US Office of Human Research Protections instituted regulations that now require all researchers to gain certification in research ethics; this training is generally provided by new, on-line certificate programs, which take about 1 hour to complete. Otherwise, IRB membership is open to people with no specific knowledge, training or experience in conducting ethical reviews.

Regarding the scope of their authority, one major concern is that IRBs in USA derive their regulatory power from the conditions attached to federal funding; hence, privately funded research does not fall under the purview of IRB review but fall only under FDA inspection as it pertains to applications for licenses to sell new drugs or devices (Berg et al., 2001). Currently in USA, the volume and investment of health research conducted by the pharmaceutical industry exceeds that of publicly funded research (Bodenheimer, 2000; Rettig, 2000). While many private corporations have voluntarily adopted the federal code of ethics regulating health research, they are not mandated by law. In a recent report, Levinson (2007) found that FDA regulators do not know how many clinical trials are being conducted, audit less than $1 \%$ of the testing sites, and have only 200 inspectors to police an estimated 350,000 testing sites. Oversight of drug trials funded by private pharmaceutical companies in international settings is even less well monitored.

Critics have also pointed out that IRBs are accountable to no one, except the courts in instances when the institution is sued by participant(s) to redress allegations of harm (Berg et al., 2001). Presently, if researchers, 


\section{An Emerging Public Health Ethics Perspective}

participants, community members, or other third parties disagree with the decision to approve or not to approve the research by the IRB, or with any stipulations that are attached or not attached for modifying the protocol, there are no provisions or standing body for appeal where they can plead their case and seek remediation.

Finally, largely as a result of the cumulative impact of the above factors, concerns have also been raised about the allegiance of IRBs. Faced with growing fears of litigation and liability, several commentators have noted that IRBs appear to have adopted a narrow 'regulatory model', focusing on meeting the letter of the law (e.g., ensuring that all eight elements are spelled out in an approved consent form), which appears to be aimed primarily at providing legal protection for the institution (London, 2002; Dawson and Kass, 2005). Capturing these concerns, in ruling on a lawsuit pressed by two families against Johns Hopkins' Kennedy Krieger Institute in their controversial Lead Paint Abatement Trial, the Maryland Court of Appeals issued a blistering critique that referred to the Hopkins IRB as 'in-house agents' who were not 'as sufficiently concerned with ethicality of the research as they were with the success of the experiment' (Maryland Court of Appeals, 2000).

In succinct summary, the Office of the Inspector General of the US HHS issued a report on IRBs that concluded: 'IRBs are reviewing too much, too quickly, with too little expertise; conducting minimal continuing review of approved research; facing conflicts of interest that threaten their independence; and providing little training for clinical investigators and board members' (Brown, 1998).

In recent years, there has been growing attention to ethics from a public health perspective (Kass, 2001; Childress et al., 2002; Buchanan and Miller, 2006b; Buchanan and Miller, 2006c). Where medicine focuses on individual health, public health is concerned with the health of the entire population. Thus, in contrast to a fiduciary duty to the individual patient, public health ethics is founded on societal responsibility to protect and promote the health of the population as a whole. The moral obligation to protect population health holds important implications for identifying appropriate ethical norms to guide research ethics, including that conducted in international settings.

The emerging public health ethics framework builds on a line of reasoning that has focused on the role of justice in evaluating the conduct of health research; in so doing, it gives greater weight to concerns for the collective good relative to the current emphasis on individual rights (McCarthy, 1998; Kass, 2004). As mentioned, observers have noted a 'paradigm shift' in the evolution of public concerns about health research in USA, moving from a preoccupation with protecting participants from harm to an interest in improving access to clinical trials (Powers, 1998). In the historical context of public outrage at the egregious misconduct of researchers at Tuskegee and other research scandals, the Belmont Report concentrated accordingly on justice considerations internal to the research process (National Commission, 1979). Although concerns about distributing the benefits of research fairly in society are presented, the report focused primarily on protecting research participants from harm and exploitation. Over time, however, the weight of public moral concerns has shifted, from worries about the risks of participating in research to greater recognition of the potential benefits. For example, the research community once thought that women should be excluded from health research due to a perceived greater vulnerability. Later, they recognized that it was unfair to conduct research only on men, since the benefits of the research for women would remain uncertain and justice demands that the benefits be distributed fairly (Dresser, 1992; Kahn et al., 1998; Weijer and Crouch, 1999). Thus, the inclusion of various population groups is now seen to be obligatory. The demands of justice have expanded the range of parties that ought to be considered morally relevant beyond the participants alone in determining the acceptability of the research under consideration.

From a public health perspective, the range of risks and benefits that are considered ethically significant must be extended to take into account the social impact of the research (Buchanan and Miller, 2006b, 2006c). In ethical reviews, research is ultimately justified on the basis of its social value; research without any social or scientific value cannot be justified because it would place participants at risk for no reason, that is, without compensating social benefit (Emanuel et al., 2000). To determine the social value of research, a comprehensive analysis should then consider not only the risks and benefits to the research participants themselves, but also the benefits and risks to the population as a whole. Adopting a public health perspective thus entails the moral obligation of researchers to consider the interests of the community as a whole as well as the individual research participants.

A public health perspective on research ethics is based on due recognition of the inherently social purpose of health research. The evolution of ethical standards regulating health research (which has been dominated historically by clinical medical research) can be traced directly 
to the Hippocratic Oath and the decree that physicians have an unqualified duty of fidelity to each individual patient (Miller and Brody, 2003; Miller and Rosenstein, 2003). Due to its historical development within the context of clinical medical trials, the currently prevailing research ethics framework has focused virtually exclusively on protecting and benefiting individual participants, to the neglect of weighing the consequences of the research for the community as a whole. While this standard may be appropriate in the context of providing medical care, research results have implications for the whole of society. Unlike the clinical context of providing personalized doctor-patient care, in the context of conducting research, the moral consequences of inadvertently inflicting harm-of conducting a trial that turns out to increase risk of serious morbidities or death-extend beyond the individual to the community at large. The consequences of the conduct of the research include, for example, the perceived trustworthiness of health research, the perceived value of health science, and the likelihood of community-wide adoption of a new intervention (e.g., HIV vaccine), should one eventually become available. In contrast to basing standards on ethical norms appropriate to providing individual medical care, a public-health perspective provides the theoretical foundation for incorporating due consideration of community interests in setting ethical standards for the conduct of health research.

\section{The Ethical Justification for Community Oversight}

As developed here, an ethical standard that requires community oversight of health research is justified on three principled grounds: respect for community autonomy and their right to self-determination; due consideration of the consequences of the research for the community as a whole; and, a more complete understanding of human autonomy. Respect for community autonomy entails the fundamental right of community members to exercise a meaningful role in determining the conduct of research that affects their lives (Buchanan et al., 2007). Vaccines, for example, are designed not only to protect individuals but to protect the community as a whole, including unvaccinated individuals via herd immunity, but this can be achieved only if a large proportion of the population gets vaccinated. Requiring community review is warranted on the basis that communities are distinguishable entities and that must be protected accordingly (Weijer, 1999; Brody et al., 2005).

The principle of respect for community autonomy acknowledges that the community has a non-negligible stake in the decision to conduct research on its membership. The community, for example, has a collective right to participate in decisions regarding the use of limited fiscal or social resources (e.g., health clinic personnel and facilities). Since justice demands that resources be allocated fairly, the community must have a say in determining whether scarce resources are being diverted from more pressing priorities or result in other potentially important opportunities being lost (Brody et al., 2005). This right encompasses protection against exploitation, where exploitation is defined as one party taking unfair advantage of another. As Wertheimer (1996) explains, for exploitation to occur, it is not necessary for one party to harm another-only that the benefit to one side be disproportionate compared to the benefit to the other. Given the enormous power of the pharmaceutical and academic health research enterprise, it is critically important to establish a body with sufficient standing to set fair terms of participation and protect against the potential for exploitation. For our purposes here, it is worth recalling that, etymologically, the word 'autonomy' originally referred not to individuals but to relationships among city-states and communal independence from imperial domination (Hill, 2001).

In addition to problems of diverting scarce resources and exploiting community assets, the community bears other types of risks that cannot be reduced to the individual level. The success of many health interventions depends on their adoption by the population. To the extent that the conduct of the research reinforces negative attitudes (e.g., human beings as 'guinea pigs'), it undermines trust in Western health science, which will impede the adoption of effective interventions. Likewise, the community as a whole must understand the implications of participation in certain types of research; seroconversion due to participation in HIV/AIDS vaccine trials, for example, has high potential for family, workforce and community disruption if there is not a widespread understanding of its significance. The use of public resources also calls for public accountability, a standard that transcends individual consent and is not now part of REC review. If researchers claim that making referrals to a research project will not take an inordinate amount of staff time, a body is necessary to monitor whether it is interfering with the timely care of patients waiting for an appointment.

The community should also have the capacity to determine the fair terms of benefits in return for their participation. The so-called 'ancillary duties' of researchers have received increasing attention in recent years, taking 
up questions about the extent of researcher obligations, for instance, to share the results with the community, to offer related health services (e.g., HIV testing and counseling), and to provide medical care for the participants (Belsky and Richardson, 2004; Macklin, 2004). The key point here is that the scope of fair, nonexploitative benefits can be decided and endorsed neither by individual participants nor by research institution-based RECs but only by the community itself.

Finally, the ethical justification for community oversight can be established on the basis of a more complete understanding of human autonomy, in particular, as it relates to conceptualizing human identity. In liberal Western societies, starting in the writings of Hobbes and Locke, conceptions of personhood have evolved in the direction of a radically individualistic, atomistic view of the human condition (Taylor, 1985). In this line of thinking, society and social cooperation come to exist only for the instrumental pursuit of individual interests, and social norms are perceived to be fundamentally antagonistic towards the unfettered quest for maximizing personal pleasure. This set of assumptions about human identity presses toward the position that the only right that warrants recognition is the right of individuals to choose not to participate.

In contrast, a number of other schools of thought, including communitarianism, feminism and non-Western traditions of communalism, have underscored the incoherence of such assumptions, noting that an individual's sense of identity is inextricably bound up with social relationships and membership in groups (Weijer, 1999; Lindegger and Richter, 2000; Moodley, 2002). This broader view gains traction starting with the fact that any expression of self-understanding can be articulated only in terms provided by a situated linguistic community. It is only through participation in the life of a community that one gains access to and learns the linguistic practices that make possible perceptions of self and the value of certain activities and ways of life. The very language used for claiming that one wants to do something for some reason (e.g., choosing to participate in research or not) presupposes membership in a community in which those terms have meaning. But if one can perceive certain desires only within a given cultural context, then one must have an obligation to preserve the larger social grouping and ensure its continuing vitality, for otherwise the community that reproduces the concepts that enable one to make sense of one's decisions (e.g., by discerning value in select activities) would be lost. As Taylor (1985) and others have argued, we find here a duty to protect the community in which membership provides the capacity to find satisfaction and fulfillment in proffered ways of life.

On the other side of this same coin, individuals are systematically identified by their classification into social categories; thus, individual agreements to participate in research inevitably raise questions about stigmatizing identifiable social groups (Brody et al., 2005). For example, the higher prevalence of HIV/AIDS found in Africans, which provides the primary justification for targeting Africans in AIDS prevention research, has been widely assumed to be attributable to promiscuous sexual practices, rather than other possible explanations (Epstein, 2007). In multiracial, multiethnic or otherwise diverse societies, the targeting of one group over another carries many meanings, about which the community identified for inclusion should be entitled to decide whether they find the implications of their participation acceptable. Hence, in direct parallel to the justification for respect for individual autonomy, the community has a right to protect itself against potential injuries to its self-understanding and self-respect (Taylor, 1992).

If one accepts that communities per se deserve protection and have a right to self-determination, then standards must be set to ensure community engagement in monitoring the conduct of health research. Based on the principle of community autonomy, we argue that the community is the best judge of its own interests; this position is analogous to the principle of individual autonomy, where respect is afforded the individual's right to determine his or her own best interests. Hence, a process must be put in place whereby the community can meaningfully deliberate about the implications for its own interests of participating in a research project. One process for achieving such community oversight is establishing Community Advisory Boards (CABs) (Buchanan et al., 2007). Under the conditions specified below, CABs provide a sound mechanism for securing community ratification indicating that the research goals are valuable and methods acceptable to the community, before the research is allowed to proceed.

\section{Practical Recommendations for Securing Legitimate Community Oversight}

Currently, many CABs are set up for the express purpose of gaining access to groups targeted for recruitment purposes, and individual $\mathrm{CAB}$ members are identified and selected by the researchers for their 'gate keeping' ability to open doors and provide entry to these populations (Cox et al., 1998; Strauss et al., 2001; Morin 
et al., 2003; Reddy et al., 2007). In contrast, once the ethical imperative for community oversight is acknowledged, then two key issues must be addressed. First, the body charged with responsibility for assuring community oversight must be vested with legitimate authority duly recognized by the community affected by the research to make decisions on their behalf. The second issue of critical concern here is specifying how community is defined.

While space constraint requires precluding a full discussion, in general, the two most common sources of legitimate civil authority are divine right and democratic procedures (Weber, 1915/1946; Friedman, 1990; Raz, 1990; Weijer and Emanuel, 2000; Richardson, 2002). To set up bodies with valid decision-making power, extant community norms and practices cannot be circumvented; unless decisions are made by a recognized source of legitimate authority, they will not be considered binding on community members. Thus, it is essential that researchers work within the existing system of power and authority at both the national and local levels.

The second major issue is the question of defining a community. A starting point for this discussion is the well-known distinction between geographic and sociological definitions of community (Clark, 1973; Plant, 1974). Health research projects have geographic locations ${ }^{1}$; the catchment area(s) for participant recruitment are defined in the research protocols. The research protocols will also specify the inclusion and exclusion criteria for participation, which provide the criteria for defining community sociologically (e.g., ethnic, cultural, linguistic, religious, gender, age, sexual orientation, racial, etc.).

Thus, we see two major sources of authority (leaders with inherited power and democratically elected representatives) and three major constituencies (existing authorities, residents, and potential participants) that must be acknowledged when vesting CABs with legitimate authority. Based on the preceding considerations, we make three recommendations with respect to instituting community oversight of international health research.

The first is that national health ministries and national legislatures enact policies that require community review of health research. These national policies should specify the type of authority that will be recognized in constituting CABs, the level of geographic specificity, and the types of sociologically defined communities that merit protection against potential exploitation, and thus, representation on CABs. The national assembly should also establish an appeals process for groups not previously recognized to petition for inclusion.
The second recommendation is that the make-up of CABs should accord with existing social practices for making communally binding decisions. ${ }^{2}$ In contexts where customary inherited authority is recognized, researchers must respect their executive agency and gain their approval and authorization to proceed. The ruling authority should be empowered to designate an agent or agents who will provide permission, approval and agreement on the terms and conditions of local participation. National legislation should stipulate whether any further community review is required at the local level. In other locales, there may be well-established practices of democratic decision-making and representation. There, we recommend that $\mathrm{CAB}$ members should be elected by both geographic and sociological community members (see below).

Many countries have coexisting systems of rule by inherited power and democratic plebiscites. The South African Constitution, for example, provides one model for achieving an appropriate balance between political rights to vote for representatives to legislative bodies and recognition of the authority of traditional leaders on matters at the local level. In such contexts, we recommend that both sources of communal authority be consulted. The issue of whether the respective approval processes remain separate, or be combined, leads into our final recommendation.

Third, we recommend that one of the two following models of representation on CABs be adopted at the local level. In Model A, the CAB is composed of equal numbers of representatives of the traditional authorities, democratically elected residents, and participant representatives. The $\mathrm{CAB}$ will deliberate as a whole to determine whether the research should be approved, not approved, or how it should be modified to make it acceptable to each of the three respective constituencies. In Model B, there are two separate CABs, one composed of traditional authorities, and the other of equal numbers of geographically representative residents and targeted participants. Since many sociological communities may not be formally organized, we recommend soliciting volunteers. If more people volunteer than there are seats on the board, we recommend a process of random selection to ensure fairness.

\section{Discussion}

The ethical foundations of health research are currently in a state of disequilibrium, both in international settings and in industrialized nations. Appeals to the established practices of Research Ethics Committee review and individual informed consent are inadequate, unquestionably 
in developing countries, but largely so in developed nations as well. A growing appreciation of the impact of health research on the community as a whole is precipitating a reassessment of the relative weight and understanding of the different ethical principles involved in protecting populations from exploitation. We have demonstrated here how new claims on justice oblige that the rights, harms and benefits to the community as a whole be taken into account in deliberations about the ethical propriety of research in international settings, but the analysis holds equally important implications for research in USA and other industrialized nations. To regain reflective equilibrium, an ethical framework based on a public health perspective yields a more satisfactory balance between the goals of gaining new knowledge and providing adequate protections in conducting health research for countries across the entire development spectrum.

An ethical standard requiring the establishment of CABs raises a host of issues, some of which cannot be decided a priori but will have to evolve pragmatically through experience and practice. One crucial issue that needs to be addressed immediately is the operational independence of CABs. Currently, CABs are largely set up and run by the individual research projects, which are responsible for providing trainings or other resources for their operations. This relationship of dependence is untenable. In consultation with community representatives, national governments and international sponsors need to begin discussions about sufficient set-asides to ensure the CABs' functional independence. The level of resources necessary to make CABs operationally effective and the responsibility for its provision are issues that will likely vary from setting to setting, but must be addressed as policies instituting their establishment are enacted.

The full scope of powers of CABs may also evolve in practice, probably in relation to the setting and type of research proposed (e.g., experimental versus epidemiological). At a minimum, CABs should have the same scope of powers of Research Ethics Committees in conducting prior review of research protocols, and stipulating provisions to meet recognized ethical standards. But over time, we envision that CABs play an appropriately more active role in securing greater community involvement, in making the monitoring of the research in progress more consistent, and in demanding greater accountability after the research has formally been completed. For example, there are already evolving practices of CABs calling for more in-depth assessments of community perceptions of the acceptability of the goals and methods of research, through processes such as community forums, key informant interviews, focus groups, community surveys, and so on. The reliance on such practices is now seen as part and parcel of community empowerment, respect for human rights, support for self-determination and the promotion of civic responsibility for the justice of extant living conditions in the population. It is important that these practices be periodically reviewed and the best practices codified into policy statements.

In contrast, one can readily imagine proposals to empower $\mathrm{CABs}$ to waive the right to individual informed consent (or assent), by appealing, for example, to new forms of proxy decision-making. Given the long track record of historical abuses, we cannot find support for this position at this time. In conclusion, the preceding analysis has shown how community oversight is ethically imperative to protect against exploitation, to minimize potential misunderstandings about the intent of the research, and to ensure fair terms of cooperation and standards of care.

\section{Notes}

1. The growing use of internet-based research belies this statement to some extent, suggesting a seemingly boundary-less domain. However, since the issue of concern here is specifying an identifiable community, questions raised by the use of the internet may be moot, as any meaningful sampling process capable of being generalized will require the same specification of geographic and sociological parameters (e.g., physicians practicing in the US).

2. The issue of conducting research in nations with despotic regimes and a history of human rights abuses is complicated. To the extent that CABs are permitted because they are perceived as politically neutral and non-threatening, they may foster the growth and vitality of civil society, which may prove to be beneficial for the country in time. Thus, we would not dismiss the possibility out of hand.

\section{References}

Angell, M. (1997). The Ethics of Clinical Research in the Third World. New England Journal of Medicine, 337, 847-849.

Angell, M. (2000). Investigators' Responsibilities for Human Subjects in Developing Countries. New England Journal of Medicine, 342, 967-969.

Bayer, R. (1998). What is Informed Consent? Workshop on Ethical Issues in the Conduct of HIV Vaccine Trials. Durban, South Africa. 
Belsky, L. and Richardson, H. S. (2004). Medical Researchers' Ancillary Clinical Care Responsibilities. BMJ, 19, 1494-1496.

Berg, J. W., Appelbaum, P., Lidz, C. and Parker, L. (2001). Informed Consent: Legal Theory and Clinical Practice. 2nd edn. New York: Oxford University Press.

Berkley, S. (2003). Thorny Issues in the Ethics of AIDS Vaccine Research. Lancet, 362, 992.

Biko, S. (1978). I Write What I Like. Johannesburg, South Africa: Heinemann.

Bodenheimer, T. (2000). Uneasy Alliance: Clinical Investigators and the Pharmaceutical Industry. New England Journal of Medicine, 342, 1539-1544.

Brody, B. A., McCullough, L. B., and Sharp, R. R. (2005). Consensus and Controversy in Clinical Research Ethics. JAMA, 294, 1411-1414.

Brown, J. (1998). Institutional Review Boards: The Emergence of Independent Boards. Office of Inspector General, Department of Health and Human Services, OEI-01-97-00192, Washington, DC. Available at: http://oig.hhs.gov/oei/reports/oei-0197-00192.pdf; last accessed October 19, 2007.

Buchanan, D. and Miller, F. G. (2006a). Justice in Research on Human Subjects. Chap. 18. In Rhodes, Rosamond, Francis, Leslie and Silvers, Anita (eds), The Blackwell Guide to Medical Ethics. New York: Blackwell.

Buchanan, D. and Miller, F. G. (2006b). A Public Health Perspective on Research Ethics. Journal of Medical Ethics, 32, 729-733.

Buchanan, D. and Miller, F. G. (2006c). Justice and Fairness in the Kennedy Krieger Institute Lead Paint Study: The Ethics of Public Health Research on Less Expensive, Less Effective Interventions. American Journal of Public Health, 96, 781-787.

Buchanan, D., Miller, F. G., and Wallerstein, N. (2007). Ethical Issues in Community Based Participatory Research: Balancing Rigorous Research with Community Participation. Progress in Community Health Partnerships, 2, 153-160.

Caplan, A. L. (1984). Is there a Duty to Serve as Subject in Biomedical Research? IRB, 6, 1-5.

Childress, J. R., Faden, R., Gaare, R., Gostin, L., Kahn, J., Kass, N., Mastrioianni, A., Moreno, J., and Nieburg, P. (2002). Public Health Ethics: Mapping the Terrain. Journal of Law, Medicine \& Ethics, 30, 170-178.

Clark, R. (1973). 'The Concept of Community: A ReExamination'. Sociological Review, 21, 397-416.

Cox, L. E., Rouff, J. R., Svendsen, K. H., Markowitz, M., and Abrams, D. I. (1998). CABs: Their Role in AIDS Clinical Trials. Health and Social Work, 23, 290-297.

Dawson, L. and Kass, N. E. (2005). Views of US Researchers about Informed Consent in International
Collaborative Research. Social Science \& Medicine, 61, 970 1211-1222.

Dresser, R. (1992). Wanted: Single, White Male for Medical Research. Hastings Center Report, 22, 24-29.

Ekunwe, E. O. and Kessel, R. (1984). Informed Consent in the Developing World. Hastings Center Report, 14, 22-24.

Emanuel, E. (2002). Institutional Review Board Reform. New England Journal of Medicine, 347, 1285-1306.

Emanuel, E., Wendler, D., and Grady, C. (2000). What Makes Clinical Research Ethical? JAMA : The Journal of the American Medical Association, 283, 27012711.

Emanuel, E. J., Wendler, D., Killen, J., and Grady, C. (2004). What Makes Clinical Research in Developing Countries Ethical? The Benchmarks of Ethical Research. Journal of Infectious Diseases, 189, 930-937.

Emanuel, E. et al. (2004). Oversight of Human Participants Research: Identifying Problems to Evaluate Reform Proposals. Annals of Internal Medicine, 141, 282291.

Epstein, H. (2007). The Invisible Cure: Africa, the West, and the Fight Against AIDS. New York: Farrar Straus \& Giroux.

Faden, R. and Beauchamp, T. (1986). A History and Theory of Informed Consent. New York: Oxford University Press.

Friedman, R. B. (1990). On the Concept of Authority in Political Philosophy. In Raz, J. (ed.), Authority. New York: New York University Press.

Global Forum for Health Research. (2004). The 10/90 Report on Health Research 2003-2004. Geneva: Global Forum for Health Research. Available at: http://www. globalforumhealth.org/Site/002_What $\% 20 w e \% 20 \mathrm{do} /$ 005_Publications/001_10\%2090\%20reports.php; last accessed October 20, 2007.

Harris, J. (2005). Scientific Research is a Moral Duty. Journal of Medical Ethics, 31, 242-248.

Hill, T. E. (2001). Autonomy of Moral Agents. In Becker, L. C. and Becker, C. B. (eds), Encyclopedia of Ethics. New York: Routledge.

Jacobsen v Massachusetts, 197 US 11. (1905). (2002). Cited in: Gostin, L. O. (ed.), Public Health Law and Ethics: A Reader. Berkeley, CA: University of California Press.

Kahn, J., Mastroianni, A., and Sugarman, J. (1998). Changing Claims about Justice in Research: An Introduction and Overview. In Kahn, J., Mastroianni, A., and Sugarman, J. (eds), Beyond Consent: Seeking Justice in Research. New York: Oxford University Press, pp. 1-10.

Kass, N. (2001). An Ethics Framework for Public Health. 1020 American Journal of Public Health, 91, 1776-1782. 
Kass, N. (2004). Public Health Ethics: From Foundations and Frameworks to Justice and Global Public Health. Journal of Law, Medicine, and Ethics, 32, 232-242.

Levine, R. J. (1986). Ethics and Regulation of Clinical Research, 2nd edn. New Haven, CT: Yale University Press.

Levinson, D. (2007). The Food and Drug Administration's Oversight of Clinical Trials. Office of Inspector General, Department of Health and Human Services, OEI-01-06-00160, September 2007. Available at: http://oig.hhs.gov/oei/reports/oei-0106-00160.pdf; last accessed October 19.

Lindeggger, G. and Richter, L. M. (2000). HIV Vaccine Trials: Critical Issues in Informed Consent. South African Journal of Science, 96, 313-317.

London, L. (2002). Ethical Oversight of Public Health Research: Can Rules and IRBs Make a Difference in Developing Countries? American Journal of Public Health, 92, 1079-1084.

1040 Lurie, P. and Wolfe, S. M. (1997). 'Unethical Trials of Interventions to Reduce Perinatal Transmission of the Human Immunodeficiency Virus in Developing Countries'. New England Journal of Medicine, 337, 853-856.

1045

Macklin, R. (2004). Double Standards in Medical Research in Developing Countries. New York: Cambridge University Press.

MacQueen, K. M., Shapiro, K., Karim, Q. A., and Sugarman, J. (2004). Ethical Challenges in International HIV Prevention Research. Accountability in Research, 11, 49-61.

Mamdani, M. (1996). Citizen and Subject: Contemporary Africa and the Legacy of Late Colonialism. Princeton, NJ: Princeton University Press.

1055 Maryland Court of Appeals. (2001). Ericka Grimes $v$ Kennedy Krieger Institute, Inc. No. 128, September Term, 2000. Available at: http://www.courts. state.md.us/opinions/ coa/2001/128a00.

Marshall, P. (2007). Ethical Challenges in Study Design and Informed Consent for Research in Resource-poor Settings. Geneva: World Health Organization on behalf of the Special Programme for Research and Training in Tropical Diseases.

McCarthy, C. (1998). The Evolving Story of Justice in Federal Research Policy. In Kahn, J., Mastroianni, A., and Sugarman, J. (eds), Beyond Consent: Seeking Justice in Research. New York: Oxford University Press, pp. 11-31.

Miller, F. and Brody, H. (2003). A Critique of Clinical
Miller, F. G. and Rosenstein, D. L. (2003). The Therapeutic Orientation to Clinical Trials. New England Journal of Medicine, 348, 1383-1386.

Molyneux, C. S., Peshua, N., and Marsha, K. (2004). Understanding of Informed Consent in a Low-income Setting: Three Case Studies from the Kenyan Coast. Social Science \& Medicine, 59, 2547-2559.

Morin, S. F., Maiorana, A., Koester, K. A., Sheon, N. M., and Richards, T. A. (2003). Community Consultation in HIV Prevention Research: A Study of Community Advisory Boards at 6 Research Sites. Journal of Acquired Immune Deficiency Syndromes, 33, 513520.

Moodley, K. (2002). HIV Vaccine Trial Participation in South Africa - An Ethical Assessment. Journal of Medicine and Philosophy, 27, 197-215.

National Commission for the Protection of Human Subjects of Biomedical and Behavioral Research. (1979). The Belmont Report: ethical principles and guidelines for the protection of human subjects of research. Federal Register Document 79-12065. Washington DC: Department of Health and Human Welfare, US Government Printing Office.

Orentlicher, D. (2005). Making Research a Requirement of Treatment. Hastings Center Report 35, 20-28.

Plant, R. (1974). Community and Ideology. London: Routledge.

Powers, M. (1998). Theories of Justice in the Context of Research. In Kahn, J., Mastroianni, A., and Sugarman, J. (eds), Beyond Consent: Seeking Justice in Research. New York: Oxford University Press, pp. 147165.

President's Commission for the Study of Ethical Problems in Medicine and Biomedical Research. (1982). Making Health Care Decisions, Vol. 1. Washington, DC: US Government Printing Office.

Raz, J. (1990). Authority and Justification. In Raz, J. (ed.), Authority. New York: New York University Press.

Rettig, R. (2000). The Industrialization of Clinical Research. Health Affairs, 19, 129-146.

Rhodes, R. (2005). Rethinking Research Ethics. American Journal of Bioethics, 5, 7-28.

Richardson, H. S. (2002). Democratic Autonomy: Public Reasoning about the Ends of Policy. New York: Oxford University Press.

Sandel, M. (1982). Liberalism and the Limits of Justice. Cambridge: Cambridge University Press.

Strauss, R. P., Sengupta, S., Quinn, S. C., Goeppinger, J., Spaulding, C., Kegeles, S. M., and Millett, G. (2001). The Role of CABs: Involving Communities in the IC Process. American Journal of Public Health, 91, 19381943.
1075 of Clinical Trials. Hastings Center Report, 33, 1928. 
1125

Taylor, C. (1985). Atomism. In Taylor, Charles (ed.), Philosophy and the Human Sciences, Philosophical Papers, Vol. 2. Cambridge: Cambridge University Press.

Taylor, C. (1992). Multiculturalism and 'The Politics of Recognition'. Princeton, NJ: Princeton University Press.

Truog, R., Robinson, W., and Randolph, A. (1999). Is Informed Consent Always Necessary for Randomized Control Trials? New England Journal of Medicine, 340, 804-807.

Wallerstein, N., Duran, B., Minkler, M., and Foley, K. (2005). Developing and Maintaining Partnerships with Communities. In Israel, B., Eng, E., Schulz, A., and Parker, E. (eds), Methods for Community Based Participatory Research. San Francisco, CA: Jossey Bass.

Weber, M. (1915/1946). The Social Psychology of the World Religions. In Gerth, H. H. and Mills, C. W. (eds), From Max Weber: Essays in Sociology. New York: Oxford University Press.

Weijer, C. (1999). Protecting Communities in Research: Philosophical and Pragmatic Challenges.
Cambridge Quarterly of Healthcare Ethics, 8, 501513.

Weijer, C. and Crouch, R. A. (1999). Why Should We Include Women and Minorities in Randomized Controlled Trials? Journal of Clinical Ethics, 10, 100106.

Weijer, C. and Emanuel, E. (2000). Ethics: Protecting 1180 Communities in Biomedical Research. Science, 289, 1142-1144.

Wendler, D., Emanuel, E., and Lie, R. (2004). The Standard of Care Debate: Can Research in Developing Countries be both Ethical and Responsive to those Countries Health Needs? American Journal of Public Health, 94, 923-928.

Wertheimer, A. (1996). Exploitation. Princeton, NJ: Princeton University Press.

Woodsong, C. and Karim, Q. A. (2005). A Model Designed to Enhance Informed Consent: Experiences From the HIV Prevention Trials Network. American Journal of Public Health, 95, 412419. 